\title{
Aberrant Methylation Profile and Microsatellit Instability in Turkish Sporadic Colorectal Carcinoma
}

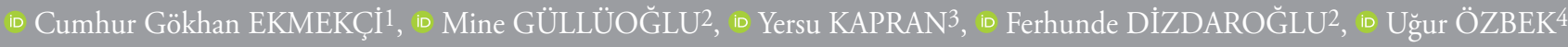

${ }^{1}$ Acıbadem Mehmet Ali Aydınlar University, LabGen, İstanbul, Turkey

2̇̇stanbul University, İstanbul Faculty of Medicine, Department of Pathology, İstanbul, Turkey

${ }_{3}^{3}$ Koç University, Faculty of Medicine, Department of Pathology, İstanbul, Turkey

${ }^{4}$ Acıbadem Mehmet Ali Aydınlar University, Faculty of Medicine, Department of Medical Genetics, İstanbul, Turkey

\section{ABSTRACT}

Objective: Genomic DNA obtained from paraffin blocks of the intended colorectal cancer cases was evaluated for promoting colorectal cancer by investigating the promoter methylation of 6 different gene promoter regions and microsatellite instability.

Methods: DNA was isolated from the paraffin tissue of 76 sporadic colorectal cancer patients by cross sections from the areas determined to be tumorous. The methylation specific PCR (MS-PCR) method was used for these DNA samples fo rmethlylation studies in promoter region of six different $A P C, h M L H 1, p 16 I N K 4 A, p 15, p 73$ and DAPK1 genes. In the same samples, the presence of microsatellite instability (MSI).

Results: The fequencey of methylation was $24 \%$ for hMLH1, 31.5\% for APC, $19.6 \%$ for DAPK1, $42.8 \%$ for p $16,30 \%$ for p15, $17 \%$ for p 73 . We calculated a methylation index ( $\mathrm{MI}=$ ratio between the number of genes methylated and the number of genes analyzed). MI was ranged from $0-0.83$, with an average of 0.271 corresponding to 1.6 genes / sample and median was 0.225 and there were 15 samples which doesn't methylated in any loci. We analysed MSI in C-kit (21\%), hMSH2 (18\%) and APC (15\%), microsatellite region.

Conclusion: We observed APC methylation was common then the other population for Turkish patient. P16 was the most commenest methylated loci among the 6 of gene and it seems storongly related with female patients. P73 was releated with left colorectal cancer and additionally it was related with the MSI.

Keywords: Epigenetic, promoter methylation, colorectal cancer, microsatellite instability, methylation specific-PCR

\section{Introduction}

Colorectal cancer (CRC) is the third most common cancer type and cause of death in the world and it is estimated that more than 1.3 million new diagnosed individuals are present in the world and CRC may cause more than 700000 deaths a year (1). The incidence varies all over the world. It was reported that India had the lowest incidence rate. On the other hand, highest incidence rates are present in developed countries $(2,3)$.

Data from immigrants show that there are also international differences. Incidence of CRC has changed very quickly in Italy, Japan, poor regions of China, and Polynesianmales in Hawaii.
Furthermore, it was highly sensitive to environment, suggesting that colon cancer is, in part, highly susceptible to environmental changes $(2,3)$. The incidence of migrants and their descendants quickly reached to the rates in countries $(4,5)$. The internationally stated rate of 20 times more frequent observation can be explained by diet habits and environmental differences in large section (2). However, it has been known that CRC is common in some families (6-8). As a result, CRC is considered as a disease associated with genetic and environmental factors.

Despite the rapid and major advances in human cancer biology, no significant increase has been observed in the overall life span and survival rates of these patients over the past three decades.

Address for Correspondence: Cumhur Gökhan EKMEKÇi, Acıbadem Mehmet Ali Aydınlar University, LabGen, İstanbul, Turkey

Phone: +90 5334141446 E-mail: cgekmekci2@yahoo.com ORCID ID: orcid.org/0000-0002-0967-172X

Cite this article as: Ekmekçi CM, Güllüoğlu M, Kapran Y, Dizdaroğlu F, Özbek U. Aberrant Methylation Profile and Microsatellit Instability in Turkish Sporadic Colorectal Carcinoma. Bezmialem Science 2019;7(2):86-94. 
Many genetic alterations leading to cancer development have been identified and technical developments have been added, and molecular profiling has been established. The formation of a molecular profile is in its broadest sense and the identification of genetic abnormalities occurs within the cell. Moreover, occurrence of events is in proteins or protein networks. These developments are promising to increase the life span and rates of the cases with diagnostic and prognostic approaches (9).

CRC develop due to accumulation of genetic and epigenetic changes. The development of CRC is assumed to primarily start with alteration of Wnt and (Transforming growth factor) TGFBeta signal pathways and than activation of KRAS followed by the inactivation of APC and TP53 (10-12). Large group of CRC (80-90\%) occurs in this order. In the remaining 10-20\%; mismatch repair system does not fulfill its function adequately which results in mutations and microsatellite instability (MSI) (10-12). Another genetic classification model of CRC describes two subtypes: Chromosomal instability (CIN) type and (MSI) type (13). First group is consisted of multiple chromosomal alterations together with P53 mutations and MSI, CpG island methylator phenotype (CIMP) on a genome wide level and BRAF mutations are observed in the second group $(13,14)$. For CRC development, DNA methylation is accepted as third underlying mechanism after CIN and MSI. Changing of gene expression due to DNA methylation may contribute CRC initiation and development (15-17). It is very well known that genome wide epigenetic alterations play important role not only in CRC but also in most of the cancers. Recently, genome wide transcriptomic studies have revealed five distinct molecular mechanisms in CRC which result in changes in genetic expression pattern (18-20).

Latest discoveries also revealed that tumor location may also be important in CRC development (left vs right side CRC). Underlying molecular mechanism of right side colon cancer development seems more relevant with MSI, CIMP and frequently BRAF mutations, and TP53 mutations are rarely seen in CRC of right side. And for left sided CRC, copy number alterations and TP53 mutations are more frequent and left sided CRC is more relevant with MSI phenotype. CIMP is observed lower in left sided CRC $(21,22)$.

Methylation profiles of CRC are widely studied to investigate and identify any molecular marker for early detection, any prognosisrelated marker, and markers for diseases classification, therapeutic target, and also for risk assesment (23-26). Early genome -wide DNA hypomethylation has been observed in CRC and LINE-1 (long interspersed nucleotide element 1) hypomethylation has been found connected with increased cancer related mortality and overall mortality in patients with CRC (27-29).

To understand methylation profile and MSI in Turkish CRC samples, we have used methylation specific-PCR technique to examine six differentially methylated tumor-suppressor genes and we analyzed three microsatellite loci for MSI. Methylation of the APC, hMLH1, p16INK4A, p15, p73 and DAPK1 promoters were performed using methylation-specific PCR in 76 sporadic CRCs. We performed these analyses on sporadic CRC samples gathered from their paraffin embedded tissue blocks. We also performed MSI analysis of same samples and together with methylation profile we performed statistical analysis based on avaliable proporties of patient.

\section{Methods}

\section{Patients and Specimens}

The samples were surgical resection specimens of consecutive patients with CRC at Istanbul University, Faculyt of Medicine hospital in Turkey. This study was a retrospective study that is why we could not take informed consent from the patients. This study was conducted in accordance with the ethical principle of Helsinki Declaration. Paraffin block samples that were stored along side were used. Data such as age, tumor type and tumor stage were used. Inclusion criteria were having resection of $\mathrm{CRC}$ and being available of tissue block of the primary tumor. Exclussion criteria were having history or pathologic evidence of familial adenomatous polyposis or idiopathic inflammatory bowel disease, or family history of hereditary non-polyposis colorectal cancer syndrome. Thus, blocks of 76 patients were selected from pathology department of Istanbul Faculty of Medicine in 2001 through 2004. While we were chosing patients from avaliable data, we aimed to select equal number of patients in terms ofsex, age, histological characterization, tumor localization and stage.

Both tumor tissue and non-neoplastic control tissue were collected from patients. Each formalin-fixed paraffin embedded (FFPE) resection specimen was microdissected and DNA extracted as reported previously (30).

\section{Microdissection from FFPE Samples and DNA İsolation}

10-15 tissue sections of a 10-micrometer-thick paraffin block taken from tumorogeneous and non-tumorogeneous distal part of the same patient were used.

First, paraffin was removed using xylene from the samples and $100 \%$ ethyl alcohol was added and the samples were precipitated. Then, tissue digestion buffer solution which includes proteinase K were added to lyse cells. Phenol/chloroform mixture (1/1 ratio) was added and centrifuged at $14.000 \mathrm{rpm}$ for 3 minutes. The supernatant was taken and this process was repeated once more. The supernatant was taken up in new tubes. Fifty $\mu \mathrm{L}$ of $5 \mathrm{M}$ ammonium acetate was added to each of the tubes. After adding the chilled $100 \%$ ethyl alcohol, it was left at $-20^{\circ} \mathrm{C}$ overnight. The next day, samples were centrifuged at $14.000 \mathrm{rpm}$ for 30 minutes, then the supernatant was taken and left for drying. Samples were allowed to stand for $10-15$ minutes at $55^{\circ} \mathrm{C}$, then $50 \mu \mathrm{L}$ of sterile $\mathrm{H}_{2} \mathrm{O}$ was added and they were allowed to stand at room temperature for at least 1 hour before measuring optical densities. Obtained DNA samples were maintained at $-20^{\circ} \mathrm{C}$ until analyses were done.

\section{Sodium Bisulfite Treatment of DNA}

DNA treated with sodium bisulfite as previously described (30). Briefly, $5 \mu \mathrm{g}$ of DNA were denaturated at $42^{\circ} \mathrm{C}$ for $30 \mathrm{~min}$ with $0.4 \mathrm{M} \mathrm{NaOH}$, incubated in $10 \mathrm{mM}$ hydroquinone, $3 \mathrm{M}$ (Sodium 
Bisulfite, Sigma, St Louis, USA) at $55^{\circ} \mathrm{C}$ for $16 \mathrm{hrs}$ and purified with the (GeneClean III kit, Bio 101, Vista, USA). Prior to ethanol precipitation, DNA was desulfonated in $0.4 \mathrm{M} \mathrm{NaOH}$ for $15 \mathrm{~min}$ at $37^{\circ} \mathrm{C}$. DNA was resuspended in water and stored at $-80^{\circ} \mathrm{C}$.

Preparation of positive controls used in methylation (In Vitro methylation).

(Sss I enzyme, New England BioLabs, Ipswich, USA), which methylates cytosines in the presence of CpG dinucleotide through whole genome, was used to generate positive controls. This process also uses S-Adenyl Methionine (SAM, New England BioLabs, Ipswich, USA), as the methyl donor group.

\section{Methylation-Specific PCR}

Bisulfite-treated DNA was used in methylation-specific PCR (MSP) reactions for 6 genes. Table 1 shows the sequences of the primers used, specific for the methylated (M) and unmethylated (U) forms. And Table 2 presents the gene regions examined for methylation and the lengths of the regions amplified in the PCR. The amplification reactions contained 25 pmoles of each primer, $200 \mu \mathrm{M}$ dNTP, $1 \mathrm{U}$ (Hotstart Taq polymerase and 1x Q buffer, Qiagen, Valencia, USA) with variable amounts of $\mathrm{MgCl}_{2}$ and cycling conditions are shown in Figure 1. All MS-PCR products were run in a $4 \%$ agarose gel.

\section{Assay for Microsatellite Instability (MSI)}

MSI was determined by fluorescently labeled PCR amplification kit for this purpose ("HNPCC Microsatellite Instability Test", Roche, Berlin, Germany). Normally, it consists of 5 markers from panel described by the American Cancer Association, International HNPCC colobaration group and German Cancer Research group. Although with this kit 5 markers were provided, we could manage to analyze only 3 loci: BAT25 (c-kit), D5S346 (APC) and D17S250 (hMSH2). Primer sequences are given in Table 3.

\section{Statiscal Analysis}

To test methylation and MSI of one locus and its relationship with other loci in terms of methylation status and to make comparisons with outcome, we used Fisher's Exact test and if the sample size was smaller than 2, then we used Pearson test. Comparison of methylation status and nonparametric outcome were tested by the nonparametric Mann-Whitney U Test. All tests were done by (SPSS software 10.0, Chicago, IL, USA) for windows and $\mathrm{p}<0.05$ was considered statistically significant with only 2 - sided results of the tests.

\section{Results}

We analyzed the methylation status of 6 genes in 76 patients with sporadic CRC (27-86 years, median age 58.8 years). We analyzed MSI in neoplastic tissue and we compared it with normal peripheral mucosa in the same patient group. Since we were particularly interested in the correlations of methylation of tumor suppressor genes previously confirmed to be methylated in CRC, we prioritized our selection of genes to include APC

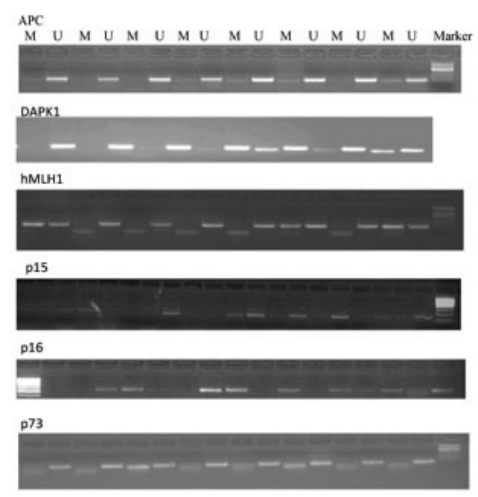

Figure 1. Agarose gel electrophoresis of polymerase chain reaction products

Table 1. Methylation and unmethylation of specific primers for each locus

DAPK1-M-F: $\quad$ 5' GGA TAG TCG GAT CGA GTT AAC GTC 3'

DAPK1-M-R: 5' CCC TCC CAA ACG CCG A 3'

DAPK1-U-F: $\quad$ 5' GGA GGA TAG TTG GAT TGA GTT AAT GTT 3'

DAPK1-U-R: $\quad$ 5' CAA ATC CCT CCC AAA CAC CAA 3'

p73

p73 M-F

5' GGA CGT AGC GAA ATC GGG GTT C 3'

p73 M-R 5' ACC CCG AAC ATC GAC GTC CG 3'

p73 U-F 5' AGG GAT GTA GTG AAA TTG GGG TTT3'

P73 U-R 5' ATC ACA ACC CCA AAC ATC AAC ATC CA3'

APC

APC M-F

APC M-R

APC U-F

APC U-R

P15

p15 M-F

p15 M-R

p15 U-F

p15 U-R

5' T C G A G A A C G C G A G CG A T T C G 3'

P16

p16 M-F 5' GACCAATCCAACCGAAACG A 3'

5' T T GAGAATGTGAGTGATTTGA 3'

5' A A C CA A T C CA A C C A AAA CA A 3'

p16 M-R

5' T T A T T A G A G GG T G GGG C G G A T C G C 3'

p16 U-F

P16 U-R

5' GT TCCAGAACCGGCGCTACAAGTG 3'

5' G C G T G C CC G A G C T A G T C CCAGTT 3'

hMLH1

hMLH1M-F

5' TTC GCGTG TAT TTT TAG GTC GGT C 3'

hMLH1M-R

5' CGA CAC AAC TCC TAC AAC GAC CG 3'

hMLH1U-F

5' TTA TGA GTA TTT GTG TGT ATT TTT AGG TTG GTT 3'

hMLH1U-R 5' CAC TAA CAA CAC AAC TCC TAC AAC AAC CA 3' 
Table 2. The gene regions examined for methylation and the lengths of the regions amplified in the polymerase chain reaction

\begin{tabular}{|c|c|c|c|}
\hline Gen & Gen Bank No. & Location of primers according to transcription start point & PCR product length (bp) \\
\hline APC & U02509 & $-17153 /-17046$ & 97 \\
\hline \multirow{2}{*}{ DAPK } & \multirow{2}{*}{ NM_004938 } & $-332 /-229$ & 103 \\
\hline & & $-332 /-234$ & 98 \\
\hline HMLH1 & AB017806 & $-526 /-661$ & 125 \\
\hline \multirow{2}{*}{ p15INK4B } & \multirow{2}{*}{ NM_004936 } & $-318 /-188$ & 130 \\
\hline & & $-312 /-187$ & 125 \\
\hline \multirow{2}{*}{ P16INK4A } & \multirow{2}{*}{ NM_000077 } & $-80 /+46$ & 126 \\
\hline & & $-80 /+44$ & 124 \\
\hline
\end{tabular}

PCR: Polymerase chain reaction, APC: Adenomatous polyposis cair, DAPK1: Death-associated protein kinase

Table 3. Primers used in determination of microsatellite instability

\begin{tabular}{|c|c|c|c|}
\hline Name of Loci & Chromosomal localization & Primer sequences & PCR product size and label \\
\hline $\begin{array}{l}\text { BAT25 } \\
\text { (c-kit) }\end{array}$ & $4 q 12-4 q 12$ & $\begin{array}{l}\text { F. 5' TCGCCTCCAAGAATGTAAGT 3' } \\
\text { R. 5' TCTGCATTTTAACTATGGCTC 3' }\end{array}$ & $\begin{array}{l}\text { 110-130bp } \\
\text { florasan } \\
\text { 6-FAM }\end{array}$ \\
\hline D5S346 (APC) & $5 q 21-q 22$ & $\begin{array}{l}\text { F. 5'ACTCACTCTAGTGATAAATCGGG 3' } \\
\text { R.5'AGCAGATAAGACAGTATTACTAGTT3' }\end{array}$ & $\begin{array}{l}\text { 100-130bp } \\
\text { florasan HEX }\end{array}$ \\
\hline
\end{tabular}

Table 4. Number of samples and their stages and their distribution according to the TNM classification based on the world health organization

\section{Stages}

Stage

Stage I

Stage II

Stage III

Stage IV

Number of sample
8
29
32
7

Number of sample

Percentage (\%)
10.5
38.2
42.1
9.2

and hMLH1. Since our patients with CRC were derived from a distinct geographical and ethnic back ground, we also wanted to revisit the pattern of methylation and included 4 genes (DAPKinase, p15, p16 and p73).

Among 76 samples, distrubition of tumor localization was as follows: $26(34.2 \%)$ rectum, $18(23.7 \%)$ sigmoid colon, 13 $(17.1 \%)$ right colon, $8(10.7 \%)$ left flexura and left colon, 7 (9.2\%) recto sigmoid, $3(3.9 \%)$ transvers colon and 1 (1.3\%) all colon cancers. Histologic and morphologic classifications were done according to the WHO's TNM classification. Most of our sample group were in stage II and III and only 7 samples were in stage IV. Table 4 represents the number of patients and their stages according to the TNM classification.

There was mucinous area in 22 samples but only 8 (10.5\%) of them were diagnosed as having mucinous adenocarcinoma. In 14 (18.4\%) samples, tumors developed from tubulo-villous adenomas. In 19 (25\%) samples, cripriform area was present. Pathologic investigation showed necrotic area in 28 and desmoplastic area in 17 samples. Additionally, there was blood vessel invasion in 13 samples, lenfatic invasion in 34 samples and perinoural invasion in 35 samples. There was no pathological tumor evidence in either proximal or distal surgical border in all samples. 
Table 5. The number and percentage of methylated samples for each locus

\begin{tabular}{|c|c|c|c|c|c|c|}
\hline & $\begin{array}{l}\text { hMLH1 } \\
\text { (\%) }\end{array}$ & $\begin{array}{l}\text { APC } \\
(\%)\end{array}$ & $\begin{array}{l}\text { P16 } \\
\text { (\%) }\end{array}$ & $\begin{array}{l}\text { P15 } \\
\text { (\%) }\end{array}$ & $\begin{array}{l}\text { P73 } \\
(\%)\end{array}$ & Dap-Kinase (\%) \\
\hline $\begin{array}{l}\text { Number of methylated samples/number of } \\
\text { analyzed samples }\end{array}$ & $\begin{array}{l}18 / 73 \\
(\% 24)\end{array}$ & $\begin{array}{l}23 / 73 \\
(\% 31.5)\end{array}$ & $\begin{array}{l}30 / 70 \\
(\% 42.8)\end{array}$ & $\begin{array}{l}20 / 64 \\
(\% 30)\end{array}$ & $\begin{array}{l}12 / 71 \\
(\% 17)\end{array}$ & $\begin{array}{l}10 / 51 \\
(\% 19.6)\end{array}$ \\
\hline APC: Adenomatous polyposis cair & & & & & & \\
\hline
\end{tabular}

Table 6. Relation of methylated loci with other methylated loci

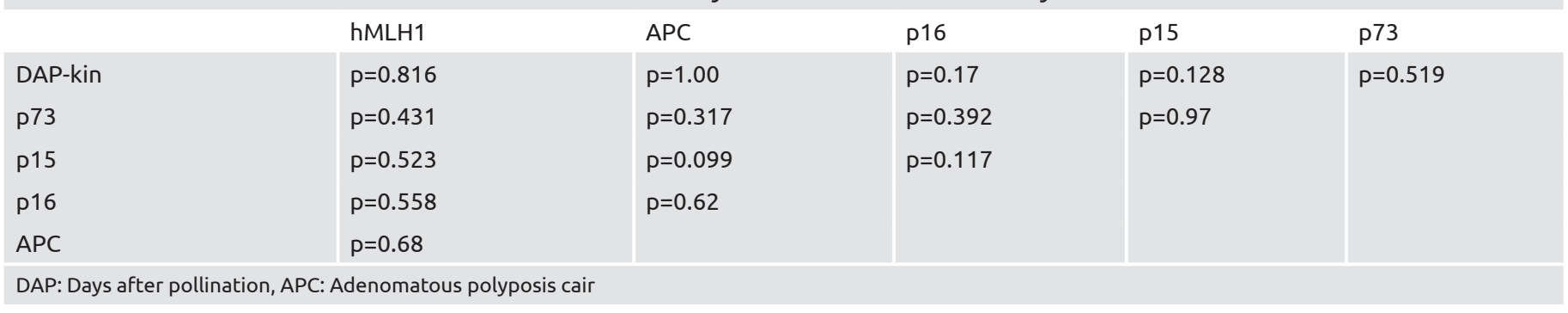

Methylation specific PCR (MSP) was used to determine methylation of p15, p16, p73, APC, DAPK1 and hMLH1. MSP reactions for each gene were first standardized using in vitro methylated DNA (IVM), which yielded a positive product with primers for the methylated form. Under our experimental MSP conditions, a consistent absence of an amplification product for the methylated form was observed in 15-20 different DNA samples obtained from peripheral blood mononuclear cells from healthy individuals. This indicated that methylation was tumor specific. Methylation was very common in CRC. In 15 samples $(19.8 \%)$ there was no detectable methylation among those six loci. The frequency of methylation of each gene varied notably. The frequency of methylation is shown in Table 5.

The frequency of methylation was $24 \%$ for hMLH1, $31.5 \%$ for APC, $19.6 \%$ for DAP-Kinase, $42.8 \%$ for $\mathrm{p} 16,30 \%$ for $\mathrm{p} 15$, and $17 \%$ for $\mathrm{p} 73$. To quantify the extent of methylation in our series of CRC, we calculated a methylation index (MI=ratio between the number of genes methylated and the number of genes analyzed) based on the 6 genes that demonstrated some degree of methylation. MI ranged brtween $0-0.83$, with an average of 0.271 corresponding to 1.6 genes/sample and median was 0.225 and when we removed 15 samples which was not methylated in any loci, the average of MI was 0.337 (represent 2.13 genes/ sample) and median was 0.33 .

For analyzing whether the coexistence of interrelationship between two different loci, we performed two-sided Fisher's exact test to understand whether one locus was methylated or un-methylated and whether methylation status of one locus was affected by another locus test results were shown in Table 6 .

We also performed MSI analysis for 3 loci by ABI Prisim 310 sequencher (Applied Biosystem, Foster City, CA, USA) in these group of samples. We compared tumor tissue samples with normal mucosal specimen for the same patients' samples. We analyzed MSI in C-kit, hMSH2 and APC micro satellite region. Among these 3 regions; for c-kit locus MSI was positive in 14 of 67 samples, for hMSH2 locus MSI was positive in 12 of 66 and for APC locus, 10 of 67 analyzed samples. In all samples; there was one locus MSI in 18 patients, 2 loci MSI in 10 patients and 3 loci MSI in 4 samples.

All the analyzed 3 loci of MSI and methylation of 6 genes were compared statistically with avaliable data (age, sex, tumor localization, tumor cell differentiation, histologic charecterization of tumor cell) of patients by SPSS 10.0 for Windows software. We observed p73 methylation was significantly related with left colon cancer ( $\mathrm{p}=0.003,2$-sided $), \mathrm{p} 16$ methylation was seen in females more than males ( $\mathrm{p}=0.029,2$-sided), $\mathrm{p} 15$ methylation was seen more related with the well differentiated tumor cells ( $\mathrm{p}=0.028,2$-sided). Also, APC methylation was correlated with stage I tumor ( $\mathrm{p}=0.05,2$-sided) and stage I tumor was related with rectum cancer $(\mathrm{p}=0.017)$. Age and methylation index were compared with the other parameters by nonparametric MannWithney U Test (SPSS for Windows software). According to test results, MSI in APC loci was positively corelated with methylation index $(\mathrm{p}=0.029)$, MSI in APC kit and c-kit loci wererelated with age $(p=0.032$ and $p=0.011$, respectively) and for both loci, instability was increasing with age. Among those 6 loci which we performed methylation analysis, only p73 methylation was related with age $(\mathrm{p}=0.017)$ and inverse relation was present between age and left colorectal cancer $(\mathrm{p}=0.015)$. MI was observed higher with stage I $(\mathrm{p}=0.006)$ and stage III $(\mathrm{p}=0.03)$ disease.

In the same patient group, MSI studies were performed using DNA samples isolated from paraffin blocks of tumor and peripheral mucosa. DNA was used from same patient group but additionaly we used paraffin blocks from distal healty region which wasalso used for MSI comparison.

The MSI kit was used for this aim and it was used to study microsatellite instability of three regions. These regions were microsatellites present in the C-kit, hMSH2 and APC regions. Microsatellite unstable tumors are tumors in which, a new allele is observed, which is not observed in healthy tissue samples, or a decrease in the number of alleles are analyzed when normal and tumor tissues are compared. 
Instability was determined in 14 of the 67 samples for the C-Kit microsatellite locus from 3 regions examined for MSI, 12 of 66 samples for the MSH2 microsatellite locus, and 10 for the APC microsatellite locus. Eighteen samples had MSI in at least one locus. MSI was observed in 2 loci in 10 specimens, 3 loci and 1 locus in 4 specimens.

\section{Discussion}

We investigated the methylation status of 6 gene regions using the methylation-specific PCR method from paraffin block samples of 76 patients with sporadic colorectal cancer. The most frequent methylation was observed in the p16 gene region $(42.8 \%)$, followed by the methylation ratios in APC, p15, hMLH1, DAP kinase and p73 regions, respectively.

In similar studies, p16 methylation was found to be $10 \%(10 / 65$, $39 \%$ of sporadic) (31), 28\% (27/97) in Americans, 27\% (13/48) in Jordanian society and $10 \%(7 / 68)$ in another study. We observed $p 16$ gene methylation more frequent in females than in males in our study population $(\mathrm{p}=0.023)$. Although $p 16$ gene methylation was more associated with mucinous carcinomas than other gene regions, there was no statistical significance $(p=0.058)$.

Pehlivan et al. (32) from Turkey studied on metastatic colon cancer samples and MSI-H group. KRAS mutations are common and found in $42.1 \%$ of their samples. They have observed P16 methylation in only one sample out of 17 samples and it was in MSI-H group.

The methylation rate for p15 with the same chromosomal location was 69\%, 39\% (44/64) for sporadic and 30\% (20/64) for our study group (31). On the other hand studies from United States did not identify any methylation on this region (33). In our study group, $p 15$ gene methylation was associated with welldifferentiated tumor cells $(\mathrm{p}=0.009)$.

There are three members of the $p 53$ gene family $(p 53, p 63, p 73)$ and transcriptional activation is specific to the sequences of gene products (34-36). Functionally, overexpression of the $p 73$ gene has been reported to activate the targets of $\mathrm{p} 53$, such as cell cycle inhibitor p21 (34-35). However, there are also significant differences between the genes that $p 53$ and $p 73$ activate. P53 and p73 proteins are involved in the development of the organism in response to DNA damage. It is known that p73 is involved in p53-like response to cell stress. Overexpression of P73 triggers apoptosis (34-37). These and similar observations suggest that p73 is a tumor suppressor gene that affects p73 expression in some tumor types. Different studies have shown that p73 broad methylation is present in different proportions and in different populations. $\mathrm{Xu}$ et al. (31) found p73 methylation in $63 \%(41 / 65)$ of the patients, whereas in our group this rate was $17 \%$. Very strong correlation was found between left colon cancer and $p 73$ gene methylation $(p=0.003)$, and we observed that MSH2 was related with MSI, so it was related with p73 methylation $(p=0.017)$. In addition, we found that the age was related with p73 methylation ( $\mathrm{p}=0.017$, Mann-Witney $U$ test) .
Apopitosis-associated protein kinase (Dap-kinase1) is involved in different apoptosis systems as a calcium/calmodilin-dependent serine/thironine kinase. However, the mechanism of triggering apoptosis is not completely understood (38). We determined in our study group that the methylation rate was $19.1 \%$ in the DAPK1 region. $\mathrm{Xu}$ et al. (31) did not identify methylation in 39 sporadic cases. Satoh et al. investigated DAPK1 methylation in a series of 9 colorectal cancers. Pehlivan et al. (32) worked on Turkish CRC samples and searched for 5 genes related with methylation and 2 of them were the same with the ones in our study (DAPK1 and p16). DAPK1 methylation was found in 53\% of of CRC samples and 29\% of methylation was in healty part of CRC. They concluded that DAPK1 was not directly related with cancer formation but it was considered as an important factor for sensitivity (32). Mutation and methylation were found in MSI -H group. In our study group, there was no association between DAPK1 methylation, any features of the disease and methylation of other gene regions.

Loss of function in the $A P C$ gene results decrease in its product, a tumor suppressor protein, that it is known as the initiator. This causes development of multi-step cancer in the large intestine (39). APC protein is directly related to $\beta$-catenin signaling proteins (40). APC proteins are located in the microvessel network in vivo, whereas in vitro they cause polymerizations of tubules into microtubules (41). Early-occurring mutant proteins lose ability to suppress the $\beta$-catenin/Tcf signaling pathway in regions close to the carboxy end of the $A P C$ gene (42).

We observed APC methylation in $31.5 \%$ of our case group. There are reports in the literature that the rates of APC methylation are relatively low (8\%) (31). Esteller et al. (43) showed the methylation of the APC region in $18 \%$ of 108 colorectal cancer cases examined. In another study, the methylation of the APC promoter was shown to be $28 \%$ of 137 colorectal cancer cases. Loss of heterozygosity and immunohistochemical staining of APC methylation are important in loss of gene expression and in the formation of second hit in the development of colorectal cancer (44).

Homozygous deletions of $p 16$ and $p 14$ genes are frequently observed in lung and breast cancers, which are not encountered in colorectal cancers (45). In contrast, methylation of p16 and p14 is more common in colorectal cancers (46). APC promoter methylation is a similar condition, although methylation in gastric cancers is a more common condition

Statistical analysis of the patient group showed that APC methylation was significantly associated only with the stage 1 disease group. This result was evaluated in the same direction as the rate limiting effect of the $A P C$ gene in the literature.

It is known that MSI, as a genetic finding, is an alternative pathway in the development of cancer after the detection of HNPCC and sporadic colorectal cancers (47). In our samples, there was a significant correlation between microsatellite instability in the APC region and hMLH1 methylation ( $\mathrm{p}=0.032)$ in the three regions where we performed the MSI study. 
HMLH1 methylation was not statistically related to MSI in the c-kit region ( $\mathrm{p}=0.054,2$-sided), and there was no significant correlation with MSI in the MSH2 region. We hypothesized that hMSH2 gene methylation may be significantly related to MSI in this region. It is reported that MLH1 and MSH2 mutations are not associated with low levels of MSI (48). It has been suggested that the methylation state in DNA repair genes which are not involved in the MMR mechanism may be the cause of the MSI (49). Interestingly, we found that only methylation in the $p 73$ gene region was significantly associated with MSI in the MSH2 region $(\mathrm{p}=0.017,2$-sided), while other methylation regions were not significantly associated with MSI screening.

Furukawa and colleagues examined hMLH1 methylation in three regions and found to be associated with MSI-H, proximal colon cancer involvement with a type of methylation, termed type 1, which contained more than $80 \%$ of the CpG island. The methylation of the PTEN promoter region was highly related with increased MSIand was claimed to be a second hit in the HMLH1 methylation (50). In our study group, the rate of HMLH1 methylation was $24 \%$ and it was found to be compatible with the literature (18\%). Our samples were consisted of sporadic patients and there was no clinical relationship except HMLH1 methylation and MSI regions.

Co-methylation of some important tumor suppressor genes have been identified in some studies and it was defined as methylator phenotype of the relevant cancer. In this study, a similar relationship for CRC was not demonstrated for the 6 regions in which we studied. The most striking aspect of our results, could be summarized as, the association of $\mathrm{p} 73$ methylation with left colon involvement, correlation with MSI, and increasedmethylation with age. More frequent observation of p16 methylation in female gender and the fact that p15 methylation was associated with well differentiated cancers were the original results of our study for Turkish society.

\section{Conclusion}

We observed that APC methylation was more common in Turkish population than other populations. P16 was the most common methylated locus among the 6 gene regions and it seemed strongly related with female patients. P73 was releated with left colorectal cancer and additionally it was related with the MSI.

\section{Ethics}

Ethics Committee Approval: This study was a retrospective study that is why we could not take informed consent from the patients.

Informed Consent: This study was a retrospective study that is why we could not take informed consent from the patients.

Peer Review: Externally peer-reviewed.

\section{Authorship Contributions}

Concept: C.G.E., M.G., F.D., Design: C.G.E., M.G., U.Ö., Data Collection or Processing: C.G.E., M.G.,
Analysis or Interpretation: C.G.E., U.Ö., Literature Search: C.G.E., Writing: C.G.E.

Conflict of Interest: No conflict of interest was declared by the authors.

Financial Disclosure: The authors declared that this study has received no financial support.

\section{Acknowledgement}

This research supported by Istanbul University research fund (Project number: T- 423/08032004).

\section{References}

1. Ferlay J, Soerjomataram I, Dikshit R, Eser S, Mathers C, Rebelo M, et al. Cancer incidence and mortality worldwide: sources, methods and major patterns in GLOBOCAN 2012. Int J Cancer 2015;136:E35986.

2. Parkin DM, Muir CS, Whelan SL, Gao JT, Ferlay J, Powell J. Cancer incidence in five continents. Lyon (France): International Agency for Research on Cancer; 1992.

3. Muir C, Waterhouse J, Mack T, Powell J, Whelan S, Smans M, et al. Cancer incidence in five continents. Lyon (France): International Agency for Research on Cancer; 1987.

4. McMichael AJ, Giles GG. Cancer in migrants to Australia: extending the descriptive epidemiological data. Cancer Res 1988;48:751-6.

5. Haenszel W. Cancer mortality among the foreign born in the United States. J Natl Cancer Inst 1961;26:37-132.

6. Veale AM. Intestinal polyposis. Cambridge (U.K.): Cambridge University Press; 1965.

7. Utsunomiya J, Lynch HT. Hereditary colorectal cancer. New York (NY): Springer-Verlag; 1990.

8. Gardner EJ. A genetic and clinical study of intestinal polyposis, a predisposing factor for carcinoma of the colon and rectum. Am J Hum Genet 1951;3:167-76.

9. Pharoah PD, Caldas C. Moleculer genetics and assessment of human cancers Experts reviews in Moleculer Medicine. Cambridge University Press ISSN 1462-3994

10. Vogelstein B, Fearon ER, Hamilton SR, Kern SE, Preisinger AC, Leppert $\mathrm{M}$, et al. Genetic alterations during colorectal tumor development. N Eng J Med 1988;319:525-32.

11. Jass JR, Whitehall VL, Young J, Leggett BA. Emerging concepts in colorectal neoplasia. Gastroenterology 2002;123:862-76.

12. Ogino S, Goel A. Molecular classification and correlates in colorectal cancer. J MolDiagn 2008;10:13-27.

13. Lengauer C, Kinzler KW, Vogelstein B. Genetic instability in colorectal cancers. Nature 1997;386:623-7.

14. Cancer Genome Atlas Network Comprehensive molecular characterization of human colon and rectal cancer. Nature 2012;487:330-7.

15. Kaneda A, Yagi K. Two groups of DNA methylation markers to classify colorectal cancer into three epigenotypes. Cancer Sci 2011;102:18-24. 
16. Toyota M, Ahuja N, Ohe-Toyota M, Herman JG, Baylin SB, Issa JP. CpG island methylator phenotype in colorectal cancer. Proc Natl AcadSci U S A. 1999;96:8681-6.

17. Shen L, Toyota M, Kondo Y, Lin E, Zhang L, Guo Y, et al. Integrated genetic and epigenetic analysis identifies three different subclasses of colon cancer. Proc Natl AcadSci U S A 2007;104:18654-9.

18. Guinney J, Dienstmann R, Wang X, de Reyniès A, Schlicker A, Soneson $\mathrm{C}$, et al. The consensus molecular subtypes of colorectal cancer. Nat Med 2015;21:1350-6.

19. Müller MF, Ibrahim AE, Arends MJ. Molecular pathological classification of colorectal cancer. Virchows Arch 2016;469:125-34.

20. Dienstmann R, Vermeulen L, Guinney J, Kopetz S, Tejpar S, Tabernero J. Consensus molecular subtypes and the evolution of precision medicine in colorectal cancer. Nat Rev Cancer 2017;17:7992.

21. Takahashi Y, Sugai T, Habano W, Ishida K, Eizuka M, Otsuka K, et al. Molecular differences in the microsatellite stable phenotype between left-sided and right-sided colorectal cancer. Int J Cancer 2016;139:2493-501.

22. Sugai T, Habano W, Jiao Y-F, Tsukahara M, Takeda Y, Otsuka K, et al. Analysis of molecular alterations in left- and right-sided colorectal carcinomas reveals distinct pathways of carcinogenesis: proposal for new molecular profile of colorectal carcinomas. J MolDiagn 2006;8:193-201.

23. Baylin SB, Jones PA. A decade of exploring the cancer epigenomebiological and translational implications. Nat Rev Cancer 2011;11:726-34.

24. Lange CP, Campan M, Hinoue T, Schmitz RF, van der Meulen-de Jong AE, Slingerland $\mathrm{H}$, et al. Genome-scale discovery of DNAmethylation biomarkers for blood-based detection of colorectal cancer. PLoS One 2012;7:e50266.

25. Lofton-Day C, Model F, Devos T, Tetzner R, Distler J, Schuster M, et al. DNA methylation biomarkers for blood-based colorectal cancer screening. Clin Chem 2008;54:414-23.

26. Warren JD, Xiong W, Bunker AM, Vaughn CP, Furtado LV, Roberts WL, et al. Septin 9 methylated DNA is a sensitive and specific blood test for colorectal cancer. BMC Med 2011;9:133.

27. Baba Y, Murata A, Watanabe M, Baba H. Clinical implications of the LINE-1 methylation levels in patients with gastrointestinal cancer. Surg Today 2014;44:1807-16.

28. Miousse IR, Chalbot MC, Aykin-Burns N, Wang X, Basnakian A, Kavouras IG, et al. Epigenetic alterations induced by ambient particulate matter in mouse macrophages. Environ Mol Mutagen 2014;55:428-35.

29. Murata A, Baba Y, Watanabe M, Shigaki H, Miyake K, Ishimoto T, et al. Methylation levels of LINE-1 in primary lesion and matched metastatic lesions of colorectal cancer. Br J Cancer 2013;109:408-15.

30. Ekmekci CG, Gutiérrez MI, Siraj AK, Ozbek U, Bhatia K. Aberrant methylation of multiple tumor suppressor genes in Acute Myeloid Leukemia. Am J Hematol 2004;77:233-40.

31. Xu XL, Yu J, Zhang HY, Sun MH, Gu J, Du X, et al. Methylation profile of the promoter $\mathrm{CpG}$ islands of 31 genes that may contribute to colorectal carcinogenesis. World J Gastroenterol 2004;10:344154.

32. Pehlivan S, Artac M, Sever T, Bozcuk H, Kilincarslan C, Pehlivan M. Gene methylation of SFRP2, P16, DAPK1, HIC1, and MGMT and KRAS mutations in sporadic colorectal cancer. Cancer Genet Cytogenet 2010;201:128-32.

33. Esteller M, Fraga MF, Guo M, Garcia-Foncillas J, Hedenfalk I, Godwin AK, et al. DNA methylation patterns in hereditary human cancers mimic sporadic tumorigenesis. Hum Mol Genet 2001;10:3001-7.

34. Jost CA, Marin MC, Kaelin Jr WG. p73 is a simian [correction of human] p53-related protein that can induce apoptosis. Nature, Sep 1997;389:191-4.

35. Osada M, Ohba M, Kawahara C, Ishioka C, Kanamaru R, Katoh I, et al. Cloning and functional analysis of human p 51, which structurally and functionally resembles p53. Nat Med 1998;4:839-43.

36. Yang A, Kaghad M, Wang Y, Gillett E, Fleming MD, Dötsch V, et al. p63, a p53 homolog at 3q27-29, encodes multiple products with transactivating, death-inducing, and dominant-negative activities. Mol Cell 1998;2:305-16.

37. Zhu J, Jiang J, Zhou W, Chen X. The potential tumor suppressor p73 differentially regulates cellular p53 target genes. Cancer Res 1998;58:5061-5.

38. Wang W-J, Kuo J-C, Yao CC, Chen R-H. DAP-kinase induces apoptosis by suppressing integrin activity and disrupting matrix survival signals. J Cell Biol 2002;159:169-79.

39. Kinzler KW, Vogelstein B. Lessons from hereditary colorectal cancer. Cell 1996;87:159-70.

40. Rubinfeld B, Souza B, Albert I, Müller O, Chamberlain SH, Masiarz FR, et al. Association of the APC gene product with beta-catenin. Science 1993;262:1731-4.

41. Smith KJ, Levy DB, Maupin P, Pollard TD, Vogelstein B, Kinzler KW. Wild-type but not mutant APC associates with the microtubule cytoskeleton. Cancer Res 1994;54:3672-5.

42. Korinek V, Barker N, Morin PJ, van Wichen D, de Weger R, Kinzler $\mathrm{KW}$, et al. Constitutive transcriptional activation by a beta-cateninTcf complex in APC-/- colon carcinoma. Science 1997;275:1784-7.

43. Esteller M, Sparks A, Toyota M, Sanchez-Cespedes M, Capella G, Peinado MA, et al. Analysis of adenomatous polyposis coll promoter hypermethylation in human cancer. Cancer Res 2000;60:4366-71.

44. Arnold CN, Goel A, Niedzwiecki D, Dowell JM, Wasserman L, Compton $\mathrm{C}$, et al. APC promoter hypermethylation contributes to the loss of APC expression in colorectal cancers with allelic loss on 5q. Cancer Biol Ther 2004;3:960-4.

45. Bisogna M., Calvano JE, Ho GH, Orlow I, Cordón-Cardó C, Borgen PI,et al. Molecular analysis of the INK4A and INK4B gene loci in human breast cancer cell lines and primary carcinomas. Cancer Genet Cytogenet 2001;125:131-8.

46. Hibi K., Nakayama H, Koike M, Kasai Y, Ito K, Akiyama S, et al. Colorectal cancers with both p16 and p14 methylation show invasive characteristics. Jpn J Cancer Res 2002;93:883-7. 
47. Ionov Y, Peinado MA, Malkhosyan S, Shibata D, Perucho M. Ubiquitous somatic mutations in simple repeated sequences reveal a new mechanism for colonic carcinogenesis. Nature 1993;363:558-61.

48. Thibodeau SN, French AJ, Cunningham JM, Tester D, Burgart LJ, Roche PC, et al. Microsatellite instability in colorectal cancer: different mutator phenotypes and the principal involvement of hMLH1. Cancer Res 1998;58:1713-8.
49. Jass JR, Iino H, Ruszkiewicz A, Painter D, Solomon MJ, Koorey DJ, et al. Neoplastic progression occurs through mutator pathways in hyperplastic polyposis of the colorectum. Gut 2000;47:43-9.

50. Goel A, Arnold CN, Niedzwiecki D, Carethers JM, Dowell JM, Wasserman L, et al. Frequent Inactivation of PTEN by Promoter Hypermethylation in Microsatellite Instability-High Sporadic Colorectal Cancers. Cancer Res 2004;64:3014-21. 